\title{
Susceptibility to tigecycline of Acinetobacter baumannii strains isolated from intensive care unit patients
}

\author{
Katarzyna Talaga ${ }^{1}$, Paweł Krzyściak ${ }^{1}$, Małgorzata Bulanda² \\ 'Department of Mycology, Chair of Microbiology, Jagiellonian University Medical College, Cracow, Poland \\ ${ }^{2}$ Department of Epidemiology of Infections, Department of Hospital Epidemiology and Infection Control \\ Chair of Microbiology, Jagiellonian University Medical College, Cracow, Poland
}

\begin{abstract}
Background: Infections caused by Acinetobacter baumannii are difficult to cure due to the acquisition of resistance by these bacteria and lead to an increase in the general costs of hospitalization. The aim of this study was to determine tigecycline susceptibility of Acinetobacter baumannii strains isolated from intensive care unit and non-intensive care unit patients with skin and soft tissue infections.
\end{abstract}

Methods: MICs were tested by Etest among 70 Acinetobacter baumannii isolates.

Results: The MIC range was from 0.5 to $8.0 \mathrm{mg} \mathrm{L}^{-1}$. For ESBL-producing Acinetobacter baumannii, as well as for strains without carbapenemases, the highest MIC to tigecycline value was $8.0 \mathrm{mg} \mathrm{L}^{-1}$. For AmpC-producing Acinetobacter baumannii, the highest MIC to tigecycline value was $6.0 \mathrm{mg} \mathrm{L}^{-1}$ and, for MBL-producing strains, $2.0 \mathrm{mg} \mathrm{L}^{-1}$.

Conclusions: The majority of Acinetobacter baumannii strains isolated from ICU and non-ICU patients demonstrated high values of MIC range, $\mathrm{MIC}_{50}$ and $\mathrm{MIC}_{90}$ to tigecycline.

Key words: Acinetobacter baumannii; antibiotics, tigecycline, susceptibility; intensive care unit, infections

Infections caused by Acinetobacter baumannii (A. baumannii), a non-fermenting bacillus, represent $15.3 \%$ of all Gram-negative bacterial infections in Poland [1]. This kind of infection is difficult to cure due to the acquisition of resistance by these bacteria, especially in intensive care units (ICUs). The development of bacterial resistance prolongs the time of treatment and raises mortality, and consequently, leads to an increase in the general costs of hospitalization $[1,2]$. The application of tigecycline may be one of the therapeutic options available [3].

Tigecycline is the first commercially available broad-spectrum glycylcycline-class anitbiotic (active against bacteria with extended-spectrum $\beta$-lactamase substrate, plasmidmediated AmpC $\beta$-lactamase and metallo- $\beta$-lactamase). The bacteriostatic effect is achieved by reversibly binding to the $30 S$ ribosomal subunit. Glycylcyclines bind to ribosomes 5 -fold more potently than tetracycline and minocycline, which explains the better efficacy of this drug [3-5]. Tigecy- cline was registered in the European Union in May 2006 for the treatment of complicated intra-abdominal infections (cIAls) and complicated skin and skin structure infections (cSSSIs), except for diabetic foot infections in adults [3-5].

\section{METHODS}

The study was approved by the local Bioethical Committee (No. KBET/19/B /2013).

\section{BACTERIAL ISOLATES}

The study involved 70 strains of $A$. baumannii isolated from patients hospitalized in intensive care units (ICUs) and other surgical (non-ICU) departments in specialist hospitals in the Cracow area in the period 2009-2013. The clinical materials were surgical wound exudates -54 samples; blood - 4 samples; peritoneal fluid -7 samples, and surgical biopsy samples -5 samples. Only one isolate per patient was accepted into the study. 
Table 1. Comparison of in vitro activity of tigecycline against $A$. baumannii strains. MIC values are given in $\mathrm{mg} \mathrm{L}^{-1}$

\begin{tabular}{lccccc}
\hline A. baumannii & MIC range & MIC $_{50}$ & MIC $_{90}$ & \% sensitive strains * & \% resistant strains * \\
\hline All strains & $0.5-8.0$ & 3.0 & 6.0 & $\mathrm{NA} / 7.14$ & $\mathrm{NA} / 80$ \\
Without carbapenemases & $0.5-8.0$ & 3.0 & 3.0 & $\mathrm{NA} / 23.80$ & $\mathrm{NA} / 52.40$ \\
ESBL & $2.0-8.0$ & 4.0 & 6.0 & $\mathrm{NA} / 0$ & $\mathrm{NA} / 94.73$ \\
AmpC & $1.5-6.0$ & 4.0 & 6.0 & $\mathrm{NA} / 0$ & $\mathrm{NA} / 93.10$ \\
MBL & 2.0 & - & - & $\mathrm{NA} / 0$ & $\mathrm{NA} / 0$ \\
\hline
\end{tabular}

MIC - minimum inhibitory concentration; $\mathrm{MIC}_{50 / 90}$ - MICs at which $50 \%$ and $90 \%$ of the isolates were inhibited, respectively; NA — breakpoints for A. baumannii not available from EUCAST; * EUCAST breakpoints for Enterobacteriaceae family

Table 2. Comparison of tigecycline activity against $A$. baumannii from ICU and non-ICU strains. MIC values are given in $\mathrm{mg} \mathrm{L}^{-1}$

\begin{tabular}{lccccc}
\hline Department & No. of strains & MIC range & $P$-value & MIC50 & MIC90 \\
\hline ICU & 36 & $0.5-8.0$ & 0.351 & 3.0 & 4.0 \\
non-ICU & 34 & $1.0-6.0$ & 0.351 & 3.0 & 6.0 \\
\hline
\end{tabular}

MIC - minimum inhibitory concentration; $\mathrm{MIC}_{50 / 90}-\mathrm{MICs}$ at which $50 \%$ and $90 \%$ of the isolates were inhibited, respectively

\section{SPECIES IDENTIFICATION AND ANTIMICROBIAL SUSCEPTIBILITY TESTING}

Species identification was carried out with API 20 NE strips (bioMérieux, Warsaw, Poland) according to manufacturer's instructions.

Susceptibility to tigecycline was evaluated by Etest (bioMérieux, Warsaw, Poland) according to manufacturer's instructions on freshly prepared Mueller Hinton II Agar (Becton Dickinson, Warsaw, Poland). The plates were inoculated with a $0.5 \mathrm{McF}$ bacterial suspension. The culture plates were incubated in ambient air at $35 \pm 1^{\circ} \mathrm{C}$ for 18-20 h. Escherichia coli ATCC 25922 and Klebsiella pneumoniae ATCC 700603 strains were used as quality control samples.

The results were expressed as $\mathrm{MIC}$ range, $\mathrm{MIC}_{50}$ and $\mathrm{MIC}_{90}$ values in $\mathrm{mg} \mathrm{L}^{-1}$ units.

\section{EVALUATION OF RESISTANCE MECHANISMS}

The presence of ESBL and AmpC phenotypes in the examined isolates were identified by double-disk susceptibility test (DDST) with ceftazidime (Oxoid, England, distributed by Argenta, Poznań, Poland) and cefotaxime (Oxoid) as indicators, and amoxicillin (Oxoid) and clavulanic acid (Oxoid) as inhibitors of ESBL. The MBL mechanism of resistance was detected by DDST with an EDTA disk, a disk containing a metallo- $\beta$-lactamase inhibitor and disks of ceftazidime (Oxoid) and imipenem (Oxoid), in accordance with the recommendations of the Polish National Reference Center for Antimicrobial Susceptibility Affairs (KORLD) based on EUCAST guidelines [6].

\section{STATISTICAL ANALYSIS}

Statistical analysis was performed using $\mathrm{R}$ Language and Environment for Statistical Computing software [7]. A $P$ value of $\leq 0.05$ was considered to be significant.

\section{RESULTS}

Tigecycline MICs for Acinetobacter ranged from 0.5 to $8.0 \mathrm{mg} \mathrm{L}^{-1}$. For ESBL-producing A. baumannii and for strains without carbapenemases, the highest MIC to tigecycline value was $8.0 \mathrm{mg} \mathrm{L}^{-1}$. For AmpC-producing A. baumannii, the highest MIC to tigecycline value was $6.0 \mathrm{mg} \mathrm{L}^{-1}$, and for MBL-producing strains, $2.0 \mathrm{mg} \mathrm{L}^{-1}$. Detailed results are shown in Tables 1 and 2, as well as Figures 1-3.

\section{DISCUSSION}

Since EUCAST has not determined in vitro breakpoints for susceptibility to tigecycline in relation to A. baumannii, conclusions should not be formally drawn as regards its sensitivity. Therefore, we compared the obtained MIC values with the distribution given by EUCAST $[8,9]$. All strains that had MIC values $\leq 1 \mathrm{mg} \mathrm{L}^{-1}$ were considered sensitive to tigecycline and all strains that had MIC $\geq 2 \mathrm{mg} \mathrm{L}^{-1}$ were deemed insensitive (resistant) [10]. EUCAST recognizes that all strains with MIC $\leq 1 \mathrm{mg} \mathrm{L}^{-1}$ do not have mutations that can lead to the acquisition of resistance (apart from a natural and known resistance characteristic for a given species - determined by the EUCAST ECOFF value is as $1 \mathrm{mg} \mathrm{L}^{-1}$ ). However, Piewngam and Kiratisin [11] suggest that the MIC breakpoint should be modified to $S \leq 0.5$ and $R>2 \mathrm{mg} \mathrm{L}^{-1}$. 


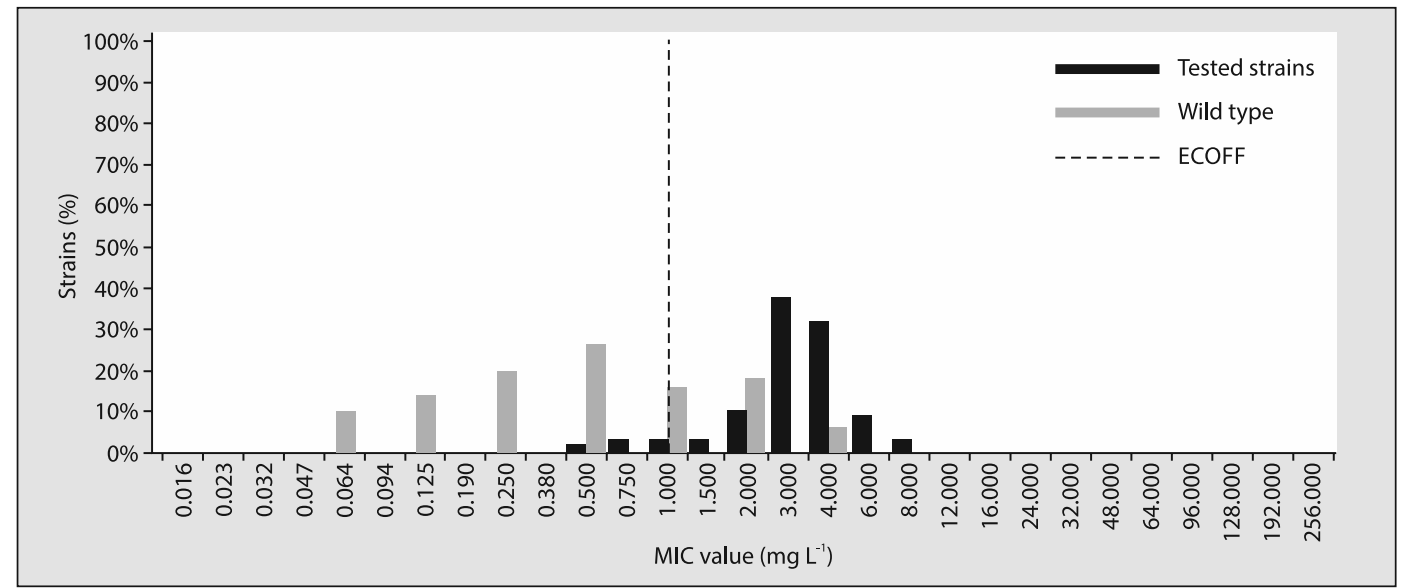

Figure 1. MIC distribution of wild type (data from EUCAST) and clinical (presented results) strains of $A$. baumannii

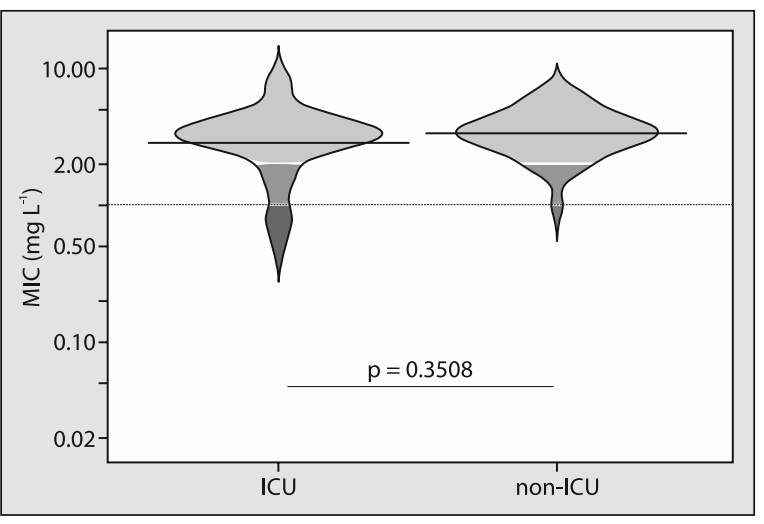

Figure 2. Comparison of MICs for A. baumannii collected from ICU and non-ICU patients showed as beanplots. Boxplots with distribution curves, susceptibility rates using the EUCAST breakpoints for Enterobacteriaceae: susceptible $<1 \mathrm{mg} \mathrm{L}^{-1}$ (dark grey), intermediate 1-2 mg $\mathrm{L}^{-1}$ (medium grey), resistant $>2 \mathrm{mg} \mathrm{L}^{-1}$ (light grey), black line - mean

It has been pointed out that the determination of the antimicrobial activity of tigecycline might vary with the use of different methods, while the disk diffusion method is not reliable as regards the determination of susceptibility to tigecycline and gives lower susceptibility rates as compared to Etest or the broth microdilution method (BMD) $[10,12]$. Zarkotou et al. [13] compared the broth microdilution method with VITEK2, Etest and MIC test strips. They found that Etest produced susceptibility results similar to those obtained with broth microdilution, while MIC values obtained by VITEK2 were higher than in the case of other tests. Moreover, a good concordance of the disk diffusion, Etest and BMD methods was found by Piewngam and Kiratisin [11].

On the other hand, there are some publications which present the opposite conclusions. Draghi et al. compared the results obtained by Etest in local laboratories with centralized broth dilution methods and found that MICs differ greatly between these methods. Therefore, for 219 strains, MIC for broth microdilution was at a lower (range 0.03-4 mg $\mathrm{L}^{-1}, \mathrm{MIC}_{50}=0.25 \mathrm{mg} \mathrm{L}^{-1}, \mathrm{MIC}_{90}=1 \mathrm{mg} \mathrm{L}^{-1}$ ) than for Etest (range 0.03-16 $\mathrm{mg} \mathrm{L}^{-1}, \mathrm{MIC}_{50}=2 \mathrm{mg} \mathrm{L}^{-1}, \mathrm{MIC}_{90}=4 \mathrm{mg} \mathrm{L}^{-1}$ ) [14]. In a more recent study, Tas et al. compared different methods for tigecycline MIC evaluation and found that the values differed between methods. Indeed, $\mathrm{MIC}_{50}=2 \mathrm{mg} \mathrm{L}^{-1}, \mathrm{MIC}_{90}=4$ $\mathrm{mg} \mathrm{L}^{-1}\left(0.1-8 \mathrm{mg} \mathrm{L}^{-1}\right)$ for microdilution and $\mathrm{MIC}_{50}=2 \mathrm{mg} \mathrm{L}^{-1}$ $\mathrm{MIC}_{90}=6 \mathrm{mg} \mathrm{L}^{-1}\left(0.1-12 \mathrm{mg} \mathrm{L}^{-1}\right)$ for Etest are very similar to the results obtained in our study $[12,14]$. As shown above, there is a great problem with obtaining reliable results of Acinetobacter susceptibility testing to tigecycline as there are no standardized guidelines, while the results from many studies have been inconclusive.

In our study, we used Etest because we believe that if this test is prepared with proper care on freshly prapared medium and a proper inoculum density, it produces reliable results when correlated with the microdilution method.

Tigecycline MICs for Acinetobacter varied from 0.5 to 8.0 $\mathrm{mg} \mathrm{L}^{-1}$ in our study. Moreover, $7.1 \%$ of the tested isolates were characterized by MIC values lower than or equal to ECOFF values and for $90 \%$ of isolates the the MIC value was $\geq 2 \mathrm{mg} \mathrm{L}^{-1}$ (the $\mathrm{MIC}_{50}$ and $\mathrm{MIC}_{90}$ values were 3 and $6 \mathrm{mg}$ $\mathrm{L}^{-1}$, respectively). Similar results indicating the presence of Acinetobacter strains with high MIC values were obtained by Piewngam and Kiratisin in a study of 290 isolates including MDR (multidrug resistant) strains from different clinical specimens from patients hospitalized at the University Hospital in Bangkok (MIC range, $\mathrm{MIC}_{50}$, and $\mathrm{MIC}_{90}$ values were $0.5-8.0 \mathrm{mg} \mathrm{L}^{-1}, 2.0 \mathrm{mg} \mathrm{L}^{-1}$, and $4.0 \mathrm{mg} \mathrm{L}^{-1}$, respectively) [11]. Navon-Venezia et al. [15] reported high tigecycline 


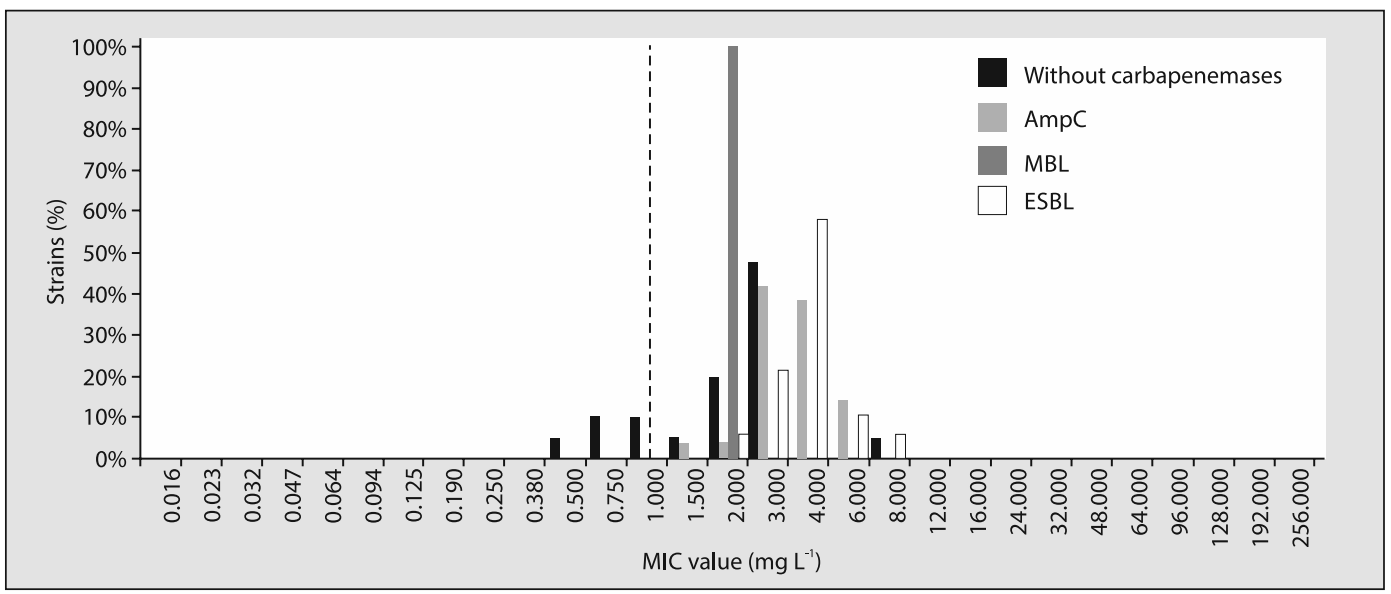

Figure 3. Tigecycline MIC distributions of $A$. baumannii. Comparison of MICs for Acinetobacter producing ESBL, AmpC, and MBL with strains without carbapenemases (presented results)

resistance in multidrug-resistant $A$. baumannii in a Tel Aviv hospital. They found that 54 of $82(66 \%)$ of the MDR A. baumannii isolates were resistant (MIC $=8 \mathrm{mg} \mathrm{L}^{-1}$ or higher), 10 of $82(12 \%)$ were intermediate (MIC 4-6 $\mathrm{mg} \mathrm{L}^{-1}$ ) and only 18 of $82(22 \%)$ were susceptible to tigecycline. The $\mathrm{MIC}_{50}$ and $\mathrm{MIC}_{90}$ values were 16 and $32 \mathrm{mg} \mathrm{L}^{-1}$, respectively, with a wide range of $\left.1.0-128 \mathrm{mg} \mathrm{L}^{-1}\right]$. These results are inconsistent with some existing studies indicating the sensitivity of Acinetobacter to this drug. The results from the Resistance surveillance program report for selected European Nations (2011) which included Poland, showed that tigecycline and colistin had significant activity against Acinetobacter, mainly A. baumannii (86\%). The MIC values were: $\mathrm{MIC}_{50}=1 \mathrm{mg} \mathrm{L}^{-1}$, $\mathrm{MIC}_{90}=2 \mathrm{mg} \mathrm{L}^{-1}$ (range from $\leq 0.03$ to $>4$ ) [16]. Moreover, Morfin-Otero and Dowzicky suggest that tigecycline's in vitro efficacy against $A$. baumannii has remained more constant than that of the other antimicrobial agents, a view based on data in their study that tigecycline showed a small increase in $\mathrm{MIC}_{90}$ values from $1 \mathrm{mg} \mathrm{L}^{-1}$ in 2004 through 2005 to $2 \mathrm{mg}$ $\mathrm{L}^{-1}$ in 2006 through 2009 [17].

Treatment of complicated intra-abdominal and complicated skin and soft tissue infections may contribute to the emergence and selection of multidrug-resistant bacterial strains in health care centres [18]. Although antibiotic resistance occurs in various hospital wards and clinics, it is best documented in the ICU. In addition, there are indications that more resistant bacteria occur in these units than in other wards [19]. For most antimicrobial agents, resistance was considerably higher among A. baumannii isolates collected from patients in ICUs than in non-ICU wards $[5,17]$. We found that $A$. baumannii strains isolated from ICU patients have significantly higher MIC values for tigecycline $\left(\mathrm{MIC}_{50}=\right.$ $\left.3.0 \mathrm{mg} \mathrm{L}^{-1}, \mathrm{MIC}_{90}=4.0 \mathrm{mg} \mathrm{L}^{-1}\right)$ than Enterobacteriaceae strains isolated from the same wards $\left(\mathrm{MIC}_{50}=1.5 \mathrm{mg} \mathrm{L}^{-1} ; \mathrm{MIC}_{90}=\right.$
$3.0 \mathrm{mg} \mathrm{L}^{-1} ;$ Wilcoxon test; $P=1.629 \mathrm{e}-09 ; \mathrm{W}=2495.5$ ) (Data not shown). However, when we compared Acinetobacter strains isolated from ICU and non-ICU patients, we did not observe any differences (Wilcoxon test, $P=0.3508$; $\mathrm{W}=$ 535.5; Fig. 2, Table 2).

In our study, $A$. baumannii strains with a MDR phenotype producing $\mathrm{ESBL}$ and $\mathrm{AmpC}$ had $\mathrm{MIC}_{50}=4.0 \mathrm{mg} \mathrm{L}^{-1}$ and $\mathrm{MIC}_{90}=6.0 \mathrm{mg} \mathrm{L}^{-1}$ and non-MDR MIC ${ }_{50} / \mathrm{MIC}_{90}=3.0 \mathrm{mg}$ $\mathrm{L}^{-1}$. Moreover, we found that strains without any resistant mechanisms for other drugs are seen on the distribution curve as a separate population with MICs below ECOFF, while strains with one or more mechanisms comprise another population (Fig. 3). That suggests that some of our strains, despite their nosocomial source, have wild type phenotypes. Eser et al. evaluated the MICs of MDR Acinetobacter and found that all strains had MICs lower than $2 \mu \mathrm{g} \mathrm{mL}^{-1}$ with $\mathrm{MIC}_{90}=1.5$ $\mu \mathrm{g} \mathrm{mL}^{-1}$ [19]. Morfin-Otero and Dowzicky (2012) found lower MIC values $\left(\mathrm{MIC}_{90}=2 \mathrm{mg} \mathrm{L}^{-1}\right)$ in MDR strains than non-MDR strains (1 $\left.\mathrm{mg} \mathrm{L}^{-1}\right)$ [17]. We checked whether isolates from sterile body sites (blood, peritoneal fluid, surgical biopsy samples) have a different susceptibility profile from strains from non-sterile body sites (wound exudates). Although we presumed that the former should display a sensitivity similar to the wild type, there was no difference observed between the strains (Wilcoxon test, $\mathrm{p}$-value $=0.186 ; \mathrm{W}=523$ ).

Our results suggest that the majority of $A$. baumannii strains isolated from ICU and non-ICU patients produce extended-spectrum beta-lactamases as ESBL or AmpC phenotype. Strains in our study were often collected from patients with chronic recurrent soft tissue and skin infections treated numerous times using various antimicrobial drugs, which favoured the selection of multi-resistant strains.

The majority of A. baumannii strains isolated from ICU and non-ICU patients demonstrated high values of MIC 
range, $\mathrm{MIC}_{50}$ and $\mathrm{MIC}_{90}$ to tigecycline. These data suggest that tigecycline cannot be an effective therapeutic option for the treatment of serious infections caused by $A$. baumannii.

\section{ACKNOWLEDGEMENTS}

1. Although a proportion of the Etest strips used was sponsored by a Polish distributor of tigecycline, this fact did not influence the obtained results. The rest of the study was financed by the grant mentioned in the acknowledgments section below.

2. This study was supported by a subsidy from the Ministry of Science and Higher Education to maintain research potential (K/ZDS/003830) from the Research Fund of the Jagiellonian University Medical College, Cracow, Poland.

\section{References:}

1. RybickiZ:Charakterystyka patogenów najczęściej wywołujących zakażenia szpitalne In: Rybicki Z (ed.): Antybiotykoterapia w problematyce zakażeń szpitalnych. $1^{\text {st }}$ ed., Makmed, Lublin 2013; 50-61.

2. Denys G, Callister SM, Dowzicky MJ: Antimicrobial susceptibility among gram-negative isolates collected in the USA between 2005 and 2011 as part of the Tigecycline Evaluation and Surveillance Trial (T.E.S.T.). Ann Clin Microbiol Antimicrob 2013; 12: 24. doi: 10.1186/1476-0711-12-24.

3. Stein GE, Babinchak T:Tigecycline: an update. Diagn Microbiol Infect Dis 2013; 4: 331-336. doi: 10.1016/j.diagmicrobio.2012.12.004.

4. Schafer JJ, Goff DA: Establishing the role of tigecycline in an era of antimicrobial resistance. Expert Rev Anti Infec Ther 2008; 5: 557-567. doi: 10.1586/14787210.6.5.557

5. Eckmann C, Dryden M: Treatment of complicated skin and soft-tissue infections caused by resistant bacteria: value of linezolid, tigecycline, daptomycin and vancomycin. Eur J Med Res 2010; 15: 554-63.

6. Gniatkowski M, Żabicka D, Hryniewicz W: Rekomendacje doboru testów do oznaczania wrażliwości bakterii na antybiotyki i chemioterapeutyki 2009. Oznaczanie wrażliwości pałeczek Gram-ujemnych. KORLD [Guidelines on the selection of tests to determine the susceptibility of bacteria to antibiotics and chemotherapeutics 2009. Determination of the susceptibility of Gram-negative bacteria. Polish National Reference Centre for Antimicrobial Susceptibility Affairs - KORLD]; http://korld. edu.pl/pdf/02-Rek2009-Paleczki_z_rodziny_Enterobacteriaceae.pdf; 14.05.2015.

7. R Core Team. A language and environment for statistical computing. R Foundation for Statistical Computing. Vienna, Austria, 2013; http:// www.r-project.org/; 14.05.2015.

8. EUCAST:Tigecycline - EUCAST Rationale document; 2006 v. 1.0; http:// www.eucast.org/fileadmin/src/media/PDFs/EUCAST files/Rationale_documents/Tigecyclinerationale1.0.pdf/; 14.05.2015.
9. EUCAST: Clinical Breakpoint Table v. 5.0; 2015; http://www.eucast.org/ fileadmin/src/media/PDFs/EUCAST_files/Breakpoint_tables/v_5.0_Breakpoint_Table_01.pdf/; 14.05.2015.

10. Grandesso S, Sapino B, Amici G et al.: Are E-test and Vitek2 good choices for tigecycline susceptibility testing when comparing broth microdilution for MDR and XDR Acinetobacter baumannii? New Microbiol 2014; 4: 503-508.

11. Piewngam $P$, Kiratisin P: Comparative assessment of antimicrobial susceptibility testing for tigecycline and colistin against Acinetobacter baumannii clinical isolates, including multidrug-resistant isolates. Int J Antimicrob Agents 2014; 5: 396-401. doi: 10.1016/j.jjantimicag.2014. 06.014.

12. Tas T, Kocoglu E, Mengeloglu Z et al.: Investigation of in-vitro susceptibility of multidrug-resistant Acinetobacter baumannii strains isolated from clinical specimens to tigecycline. Bosn J Basic Med Sci 2013; 4: 266-270.

13. Zarkotou O, Pournaras S, Altouvas $G$ et al.: Comparative evaluation of tigecycline susceptibility testing methods. J Clin Microbiol 2012; 11: 3747-3750. doi: 10.1128/JCM.02037-12.

14. Draghi D, Tench S, Jones M et al.: Surveillance of tigecycline (TIG) activity: discordance between national profiles associated with testing protocol and methods. Abstr. $46^{\text {th }}$ Int. Conf. Antimicrobial Agents Chemother., abstr. D-701 2006; 155.

15. Navon-Venezia S, Leavitt A, Carmeli Y: High tigecycline resistance in multidrug-resistant Acinetobacter baumannii. J Antimicrob Chemother 2007; 4: 772-774.

16. Jones RN, Flonta M, GurlerN et al.: Resistance surveillance program report for selected European nations (2011). Diag Microbiol Infect Dis 2014; 4: 429-436. doi: 10.1016/j.diagmicrobio.2013.10.008.

17. Morfin-Otero R, Dowzicky MJ:Changes in MIC within a global collection of Acinetobacter baumannii collected as part of the Tigecycline Evaluation and Surveillance Trial, 2004 to 2009. Clin Ther 2012; 1: 101-112. doi: 10.1016/j.clinthera.2011.11.028.

18. Fritsche TR, Sader HS, Stilwell MG et al.: Potency and spectrum of tigecycline tested against an international collection of bacterial pathogens associated with skin and soft tissue infections (2000-2004). Diagn Microbiol Infect Dis 2005; 3: 195-201.

19. Eser OK, Ergin A, Tunçkanat $F$ et al.: In vitro activity of tigecycline as a therapeutic option against multidrug-resistant Acinetobacter spp. New Microbiol 2008; 4: 535-542.

\section{Corresponding author:}

Katarzyna Talaga

Department of Mycology

Chair of Microbiology

Jagiellonian University

Medical College, Cracow, Poland

e-mail:katarzyna.talaga@uj.edu.pl

Received: 7.10.2015

Accepted: 9.03.2016 